\title{
Earthquake hazard assessment in the Australian Southwest Pacific Region. A review of the status quo
}

\author{
David Denham $\left({ }^{1}\right)$ and Warwick Smith $\left({ }^{2}\right)$ \\ ( $\left.{ }^{l}\right)$ Australian Geological Survey Organization, Canberra, Australia \\ $\left.{ }^{2}\right)$ Institute of Geological and Nuclear Sciences Limited, Wellington, New Zealand
}

\begin{abstract}
Since the late 1960s earthquake hazard has been assessed quantitatively for five countries in the region, which for this review comprises the continent of Australia and the active plate margin countries of Indonesia and Papua New Guinea through the Solomon Islands to Fiji and New Zealand. In each country the methods used in the assessments are invariably different and the final hazard maps display different risk parameters so it is difficult to compare levels of risk between each of the countries. For example, the most recent maps for New Zealand display expected Modified Mercalli Intensities for a number of return periods (MMVI-MMIX for 5-2000 years) whereas for Papua New Guinea the hazard is expressed as 20 year return periods for peak acceleration at $5 \%$ damping for a range of natural periods. There is a clear need to apply common methodologies and data bases throughout the whole region so that hazard estimates are consistent from country to country.
\end{abstract}

\section{Introduction}

The southwest Pacific region contains a wide range of tectonic regimes. The Australian continent, which is in the central part of the region under discussion, exhibits typical intraplate properties (Denham, 1988). It is bounded by active plate margins from Indonesia in the northwest through Papua New Guinea to the Solomon Islands, Vanuatu, Fiji and New Zealand in the southeast (fig. 1). Each segment of the plate margin experiences a different tectonic environment and has to be considered separately in the context of earthquake risk. For example the Tonga/Kermadec boundary is an oceanic/oceanic boundary with high rates of convergence $(\sim 10 \mathrm{~cm} / \mathrm{yr})$ and seismicity patterns extending from close to the surface down to $650 \mathrm{~km}$. In contrast the island of New Guinea is essentially the site of a continent/continent collision with consequential mountain building and seismicity extending to depths of only approximately $200 \mathrm{~km}$.

Given these differences in tectonic regime, it is hardly surprising that different approaches have been made throughout the region in the assessment of earthquake hazard. We found that quantitative assessments have been attempted in five countries and this review outlines the status quo in each of these. As will be revealed the techniques used and the presentation formats vary considerably. Figure 1 


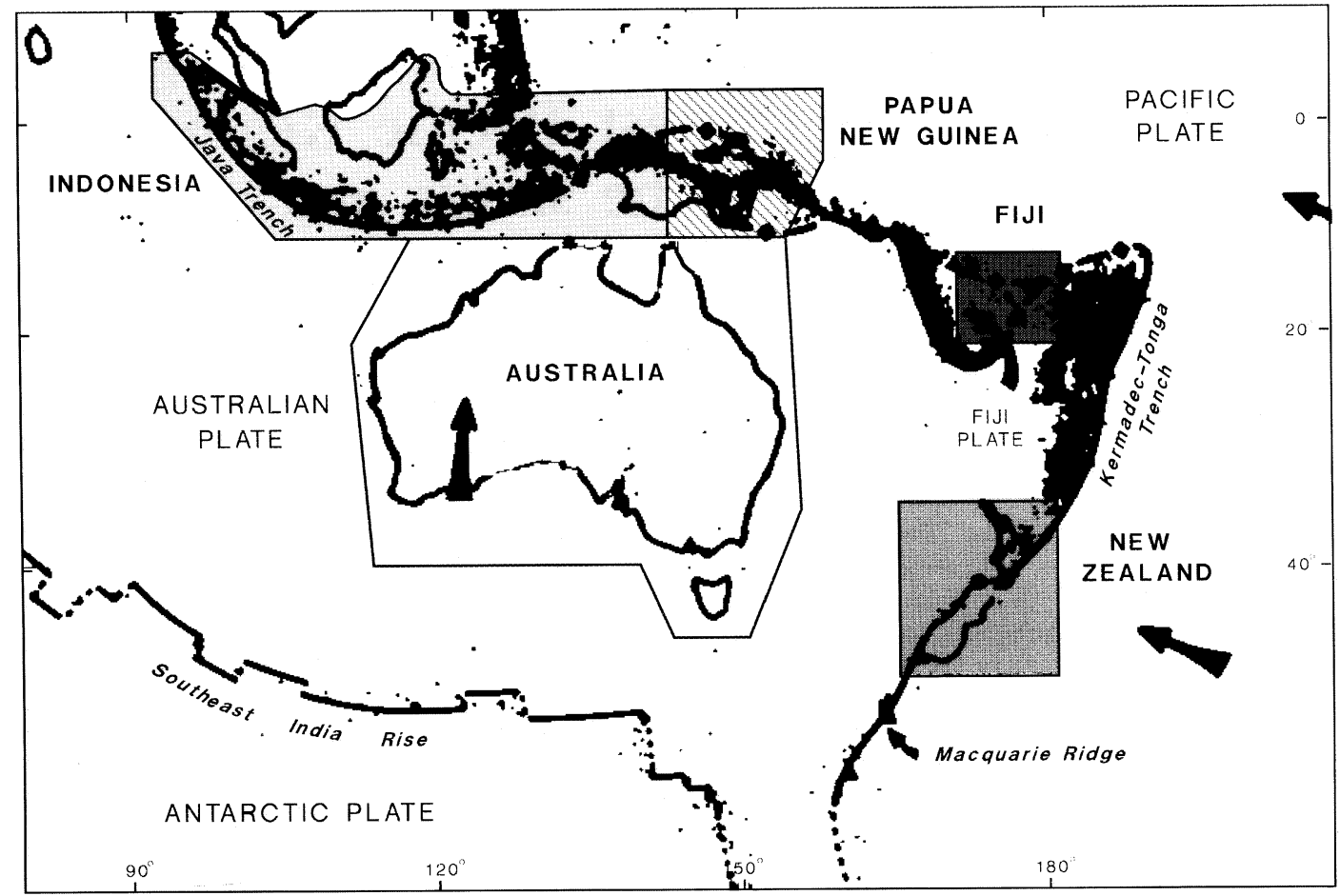

Fig. 1. Location map showing the main plate boundaries, the direction of the plate motion relative to the Antarctic plate and the regions discussed in the paper.

shows the region under consideration and the locations of the countries where quantitative assessments are available. Our approach will be to examine each country in turn.

\section{Current seismic zoning arrangements}

\subsection{Indonesia}

We found two assessments for the Indonesian region. The first was the 1979 global assessment by (Hattori, 1979). He used data from 1901-1977, converted all magnitudes to surface wave magnitudes and used an attenuation model by Kanai and Suzuki (1968) to estimate ground shaking. He used extreme value methods to determine maximum velocities and accelerations for return periods of 50, 100 and 200 years. The maximum shaking was expected in Iryan Jaya where a 50 year return period of approximately $0.2 \mathrm{~g}$ was estimated.

The second study was done in 1978 by the New Zealand engineering firm Beca, Carter, Hollings and Ferner, and an Indonesian counterpart team. The work was commissioned under the aegis of the New Zealand Bilateral Assistance Programme to Indonesia, and was done under the direction of a New Zealand Steering Committee, with the assistance of the New Zealand Department of Scientific and Industrial Research (Beca et al., 1978).

In this study Indonesian catalogues were examined to determine the historical frequency of occurrence of shallow earthquakes throughout 


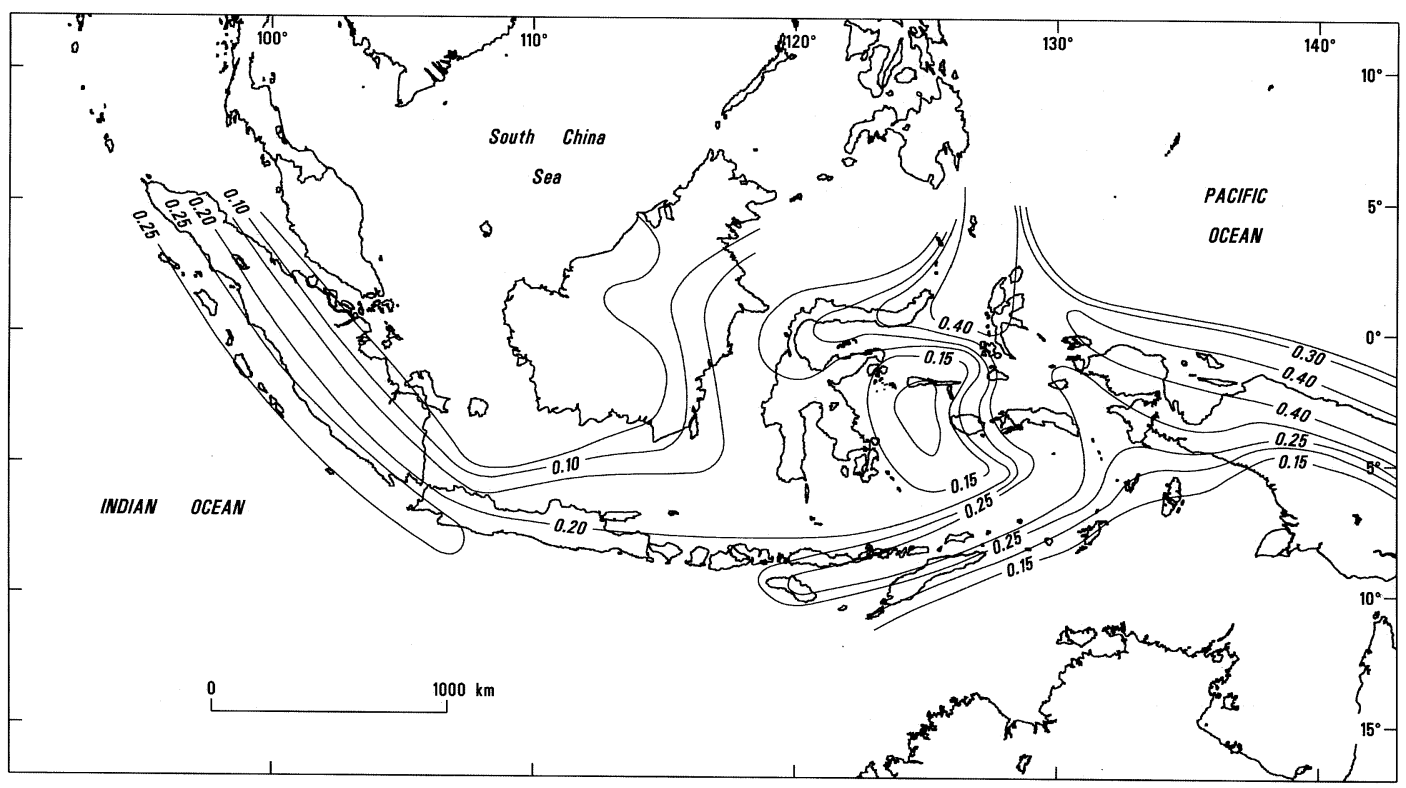

Fig. 2. 20 year return period values for peak acceleration response at $5 \%$ damping for structures of natural period 0.0 to 0.5 on soft ground (from Beca, Carter, Hollings and Ferner Ltd, unpublished report), Indonesia.

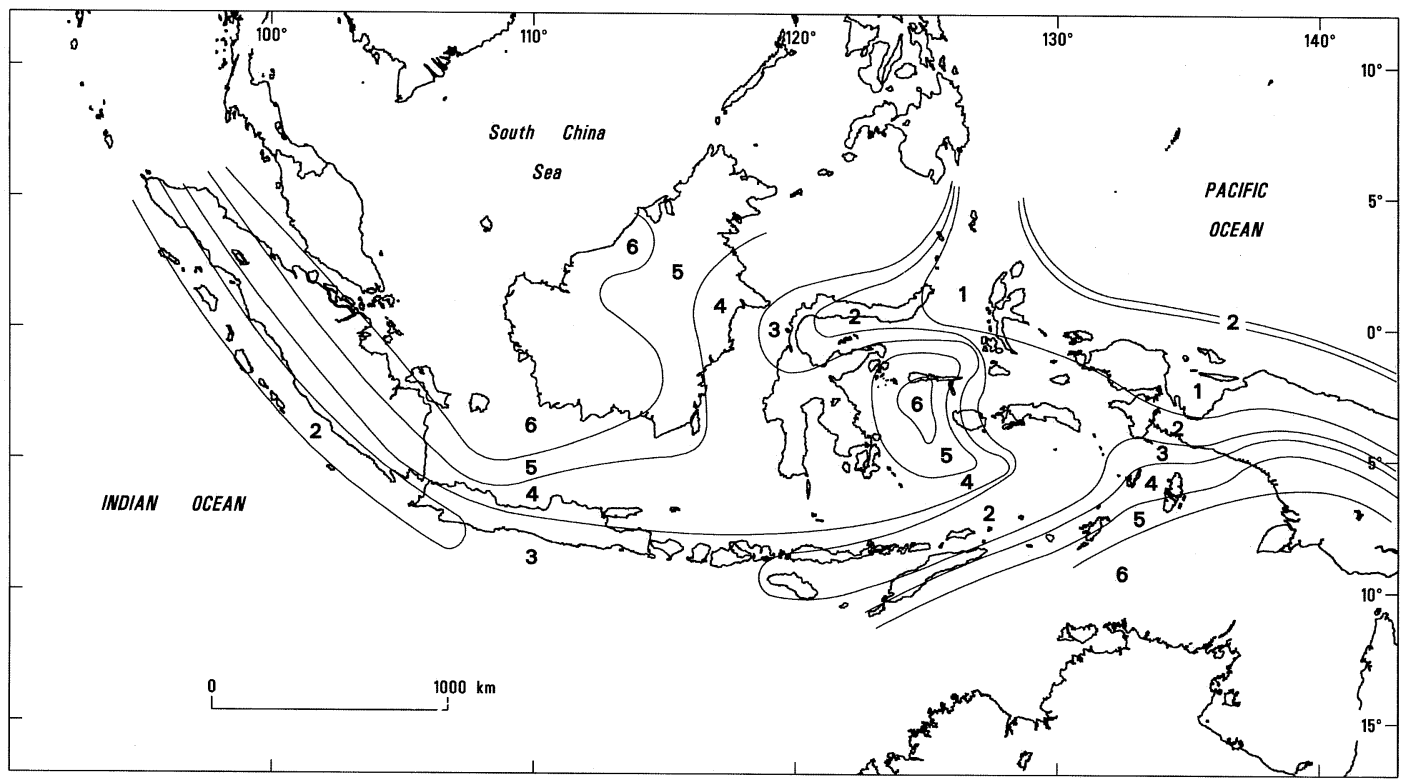

Fig. 3. Seismic zones for building construction (from Beca, Carter, Hollings and Ferner Ltd, unpublished report), Indonesia. 
the country. A review of late Quaternary deformation was undertaken, and maps prepared showing zones where deformation has occurred in the last 20000,250000 and 2-3 million years. A study of the seismotectonic units of Indonesia was also completed, and maximum magnitudes assigned to each unit. Frequencymagnitude relations and attenuation functions were determined for each unit.

The final results show contours of 20 year return period of peak acceleration response at $5 \%$ damping for periods 0.0 to $0.5 \mathrm{~s}$ on soft ground, 2.0 to 3.0 on soft ground, 0.0 to 0.25 on hard ground and 2.0 to $3.0 \mathrm{~s}$ on hard ground. Figure 2 shows the results of one of these plots and fig. 3 the six seismic zones for building construction recommended in the report. The procedures used to define the zones are not described in the public literature. However, 6 zones are outlined. These range from 1 with the highest risk, where the 20 year return period for peak acceleration is $0.35 \mathrm{~g}$ to zone 6 where the equivalent peak acceleration is expected to be less than $0.05 \mathrm{~g}$.

\subsection{Papua New Guinea}

The seismic risk estimates by Brooks (1965) for Papua New Guinea were the first published quantitative assessments in the region. He used a data set from 1906-1959 to estimate maximum intensities of shaking (MMI) for 25, 50 and 200 year return periods. Figure 4 shows the 50 year return period results for MM intensities VII, VIII, and IX.

Jury et al. (1982), using a data base from 1900-1978, determined 20 year return period values for peak acceleration response at 5\%

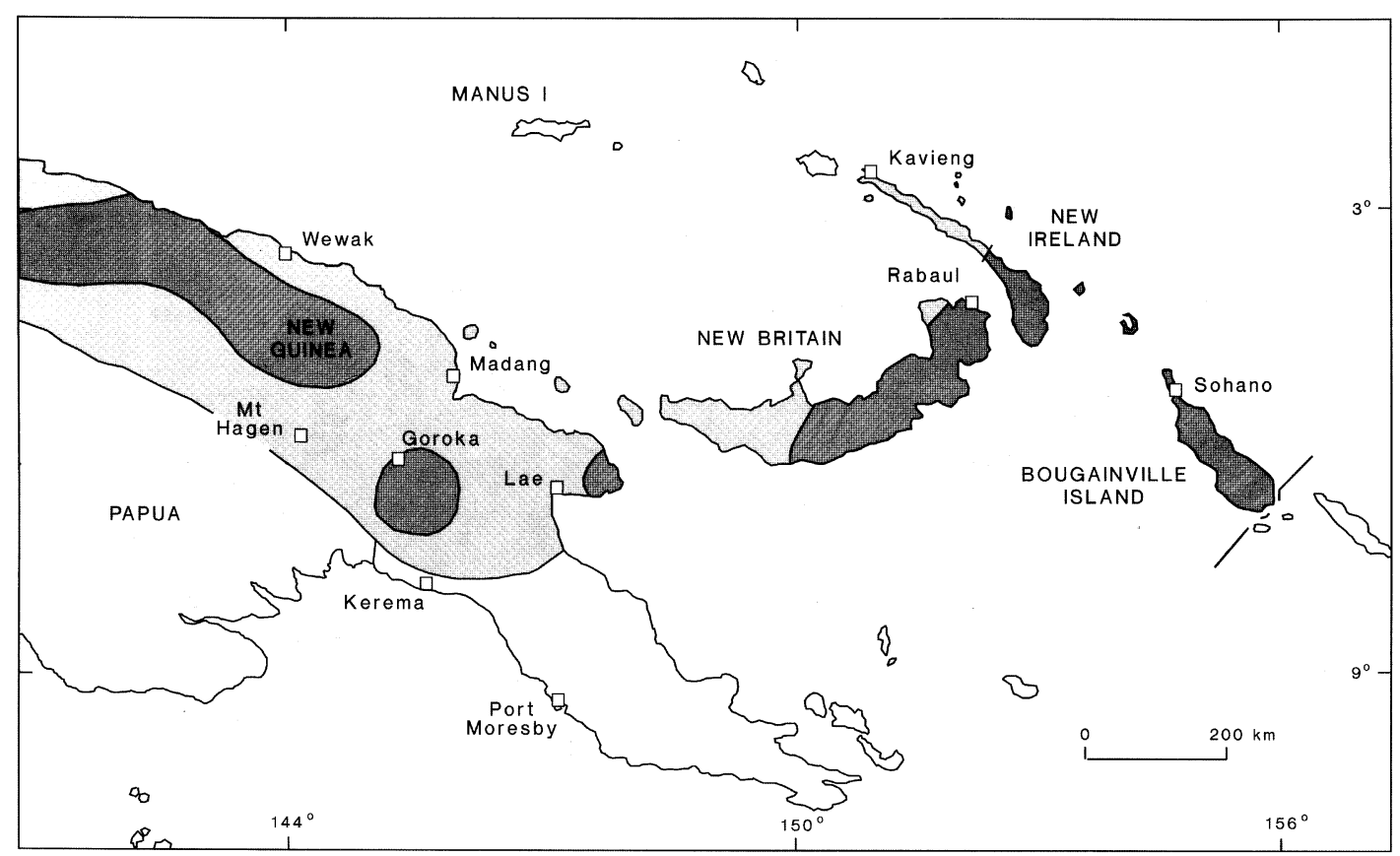

Fig. 4. Intensity zone map for Papua New Guinea from Brooks (1965), 50 year return periods for MM intensities IX, VIII, and VII (dark, medium and no stipple respectively). 
(5)

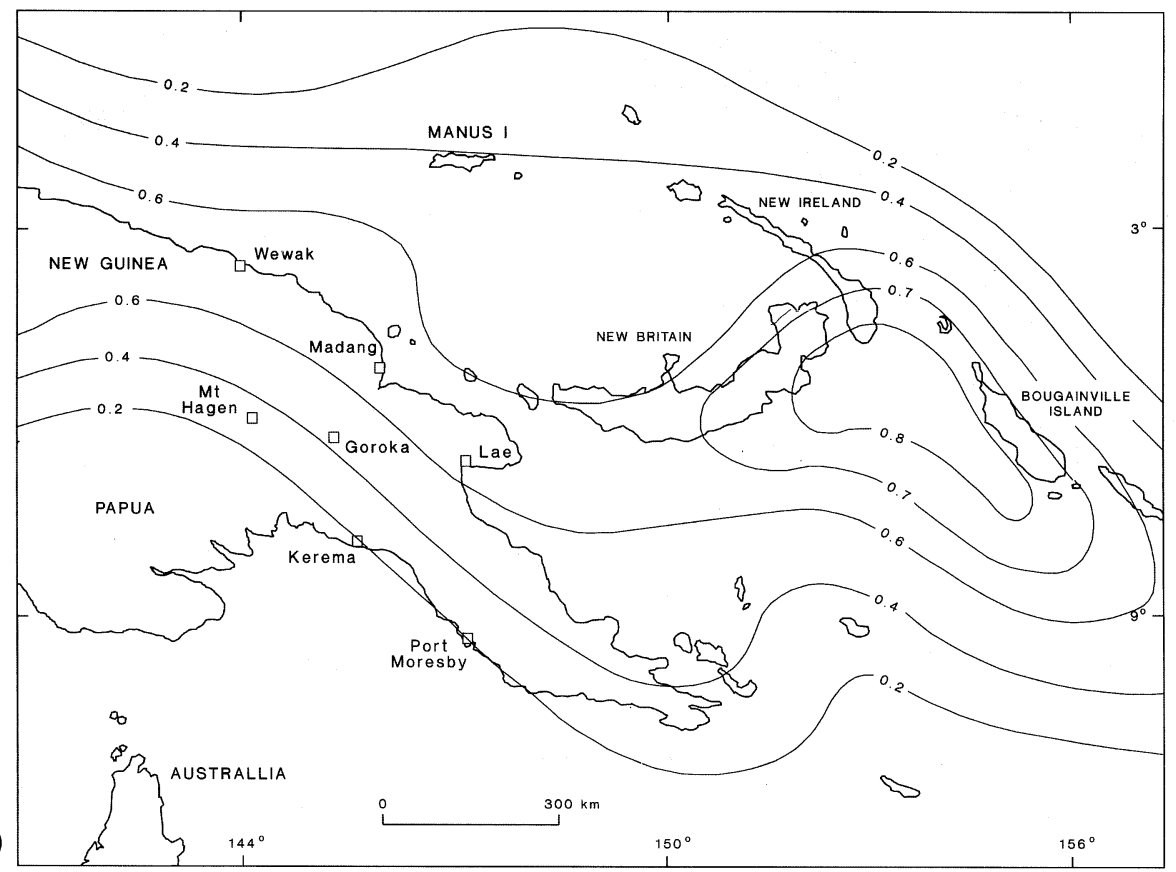

(6)

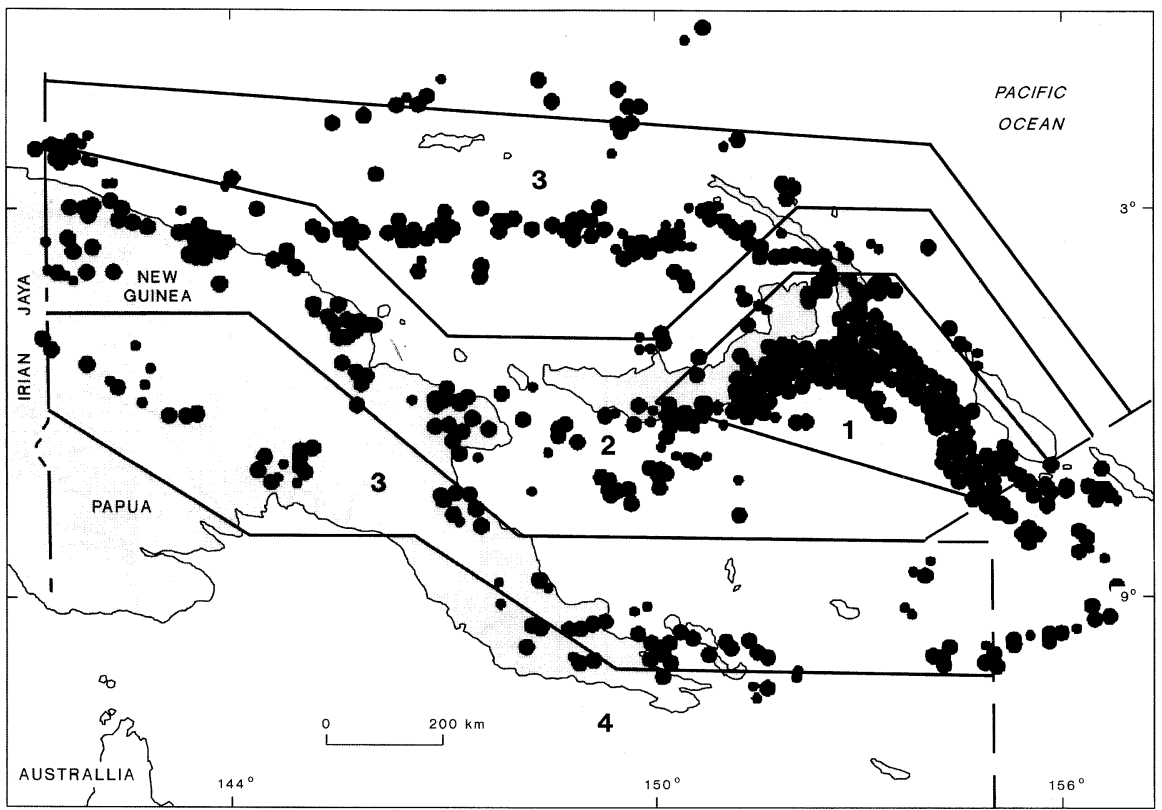

Fig. 5 (top). 20 year return period values for peak acceleration response at $5 \%$ damping for structures of natural period 0.0 to $0.5 \mathrm{~s}$ on soft ground - Papua New Guinea and Fig. 6 (bottom). Seismic zones for building construction. 


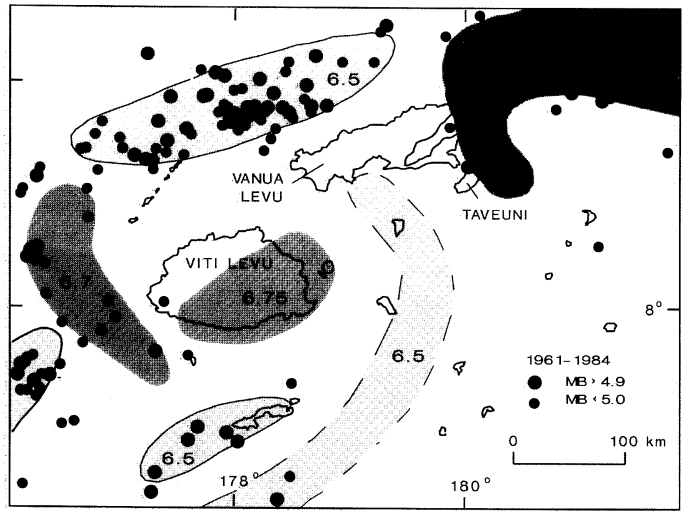

(a)

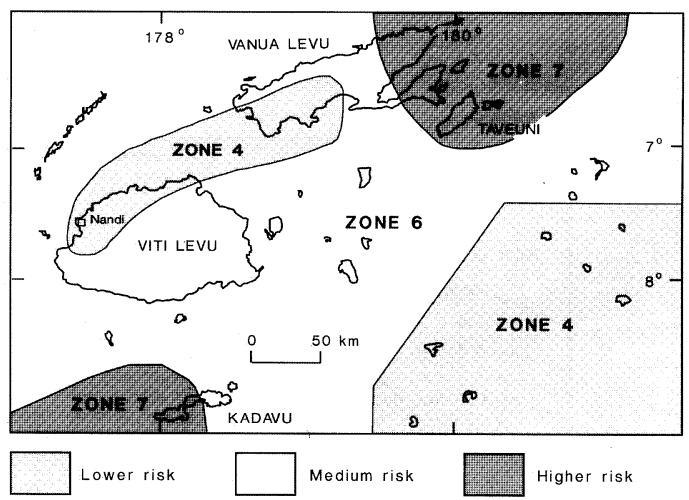

(b)

Fig. 7. a) Earthquake zones and maximum recorded magnitudes (Ms), 1961-1984; b) preliminary earthquake risk zoning map for Fiji.
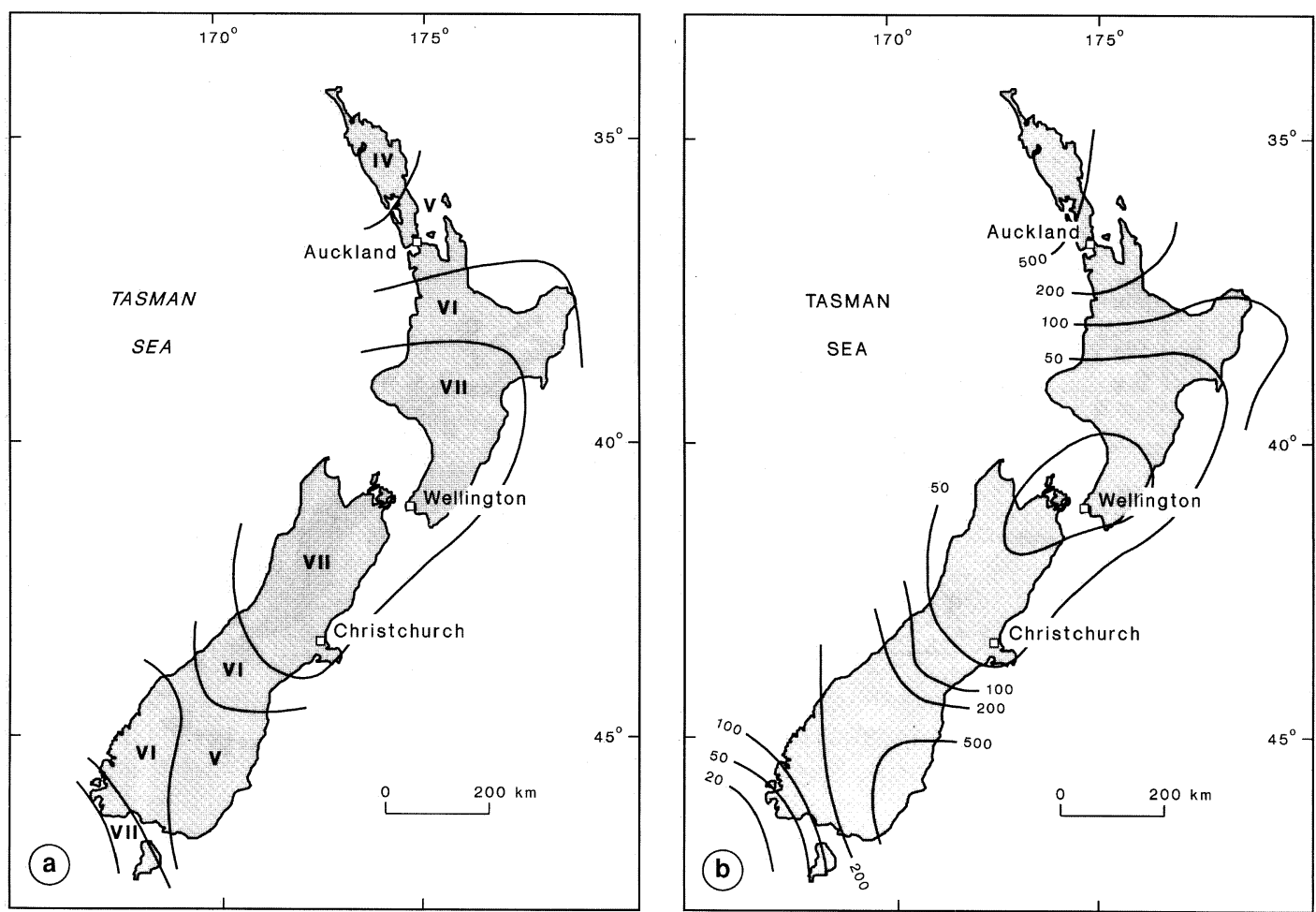

Fig. 8. a) Intensities with a return period of 50 years, the probability that these intensities will be equalled or exceeded within 50 years is $64 \%$; b) return periods for intensity MM VII and greater, based on occurrences of large earthquakes, data for both figures 1840-1975. 
damping for a range of natural periods and ground conditions. Figure 5 indicates a typical result and fig. 6 shows the seismic zones proposed for building construction.

These are still extant (pers. comm. I.D. Ripper, June 1992) in spite of arguments by McCue (1984), who pointed out that the zones in the Jury et al. (1982) study do «not correlate particularly well with either present day seismicity or tectonic models of the region». He proposed a replacement map but this has not been introduced into the Papua New Guinea Building Code. There is clearly a need for the seismic risk in Papua New Guinea to be reassessed using the better data bases and the improved methodologies now available.

\subsection{Fiji}

Using a data set from 1850-1984, Everingham (1983) estimated the cumulative frequency of earthquake intensities in various areas of Fiji. He used these results together with the maximum recorded magnitudes for earthquakes in the region from 1961-1984 (fig. 7a). Everingham recommended that most of Fiji should adopt building standards defined for zone B (NZ Code) or Zone 2 (1979 Australian Code). Jones (pers. comm. 1991) has used Everingham's results to derive a preliminary Earthquake Risk Zoning Map (fig. 7b). In this map Zone 4 has a $10 \%$ change of MM VII being exceeded in 50 years and Zones 6 and 7
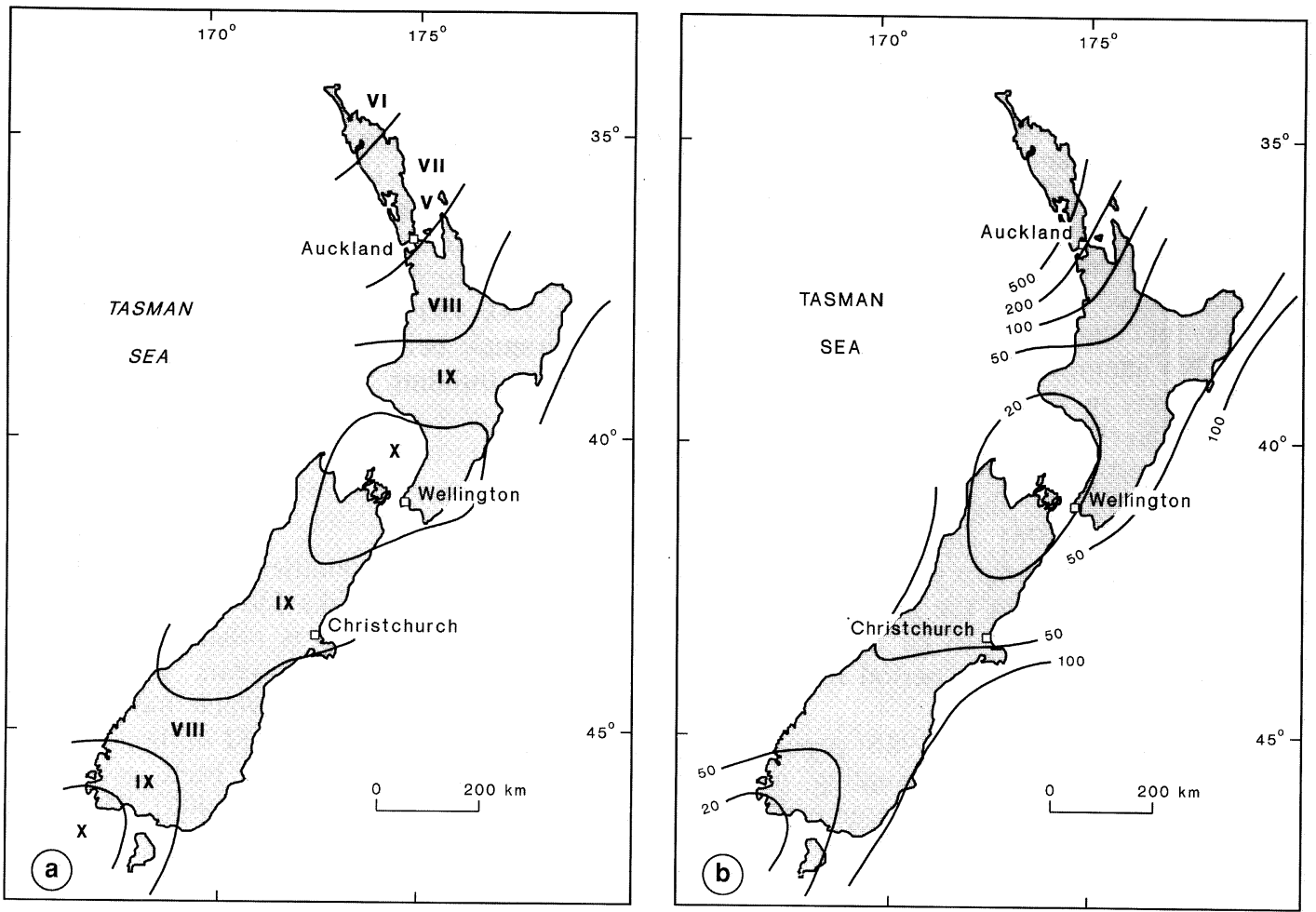

Fig. 9. a) Intensities with a $10 \%$ probability of occurrence within 50 years - data set $1840-1982$; b) mean return periods (years) for intensity MM VII. Data set 1840-1982. 
have a $10 \%$ change of MM VIII being experienced in the same period. As with Papua New Guinea, there is clearly a requirement for a proper zoning study for Fiji so that proper quantitative assessments of earthquake hazard be estimated.

\subsection{New Zealand}

New Zealand is situated on the boundary of the Australian and Pacific Plates. Since 1840 over 20 earthquakes with magnitude of 7 or greater are known to have taken place (Smith and Berryman, 1986). Several of these have caused significant damage and the presence of recent fault scarps in both the North and South Islands indicates the potential for major earthquakes taking place.

The first study on New Zealand was published by Smith (1976). He used a data set extending from 1840-1975 and computed cumulative frequency distributions of intensities to obtain return periods for Modified Mercalli intensities ranging from VI to IX for periods of 50 and 1000 years. Figure $8 \mathrm{a}$ ) and b) show two of the maps. Smith assumed that the past record is representative of what will happen in the future to carry out his calculations and also determined a series of intensity/distance curves for earthquakes of different magnitudes. No attempt was made to derive ground accelerations or velocities.

Two later papers by Smith (1978a and $1978 b)$ investigated the intensity decay with distance for each of the three regions defined earlier (Smith, 1976) and these pages contained estimates of return periods for Modified Mercalli intensities for the major urban areas. Wellington turned out to be the highest risk city with expected return period for MM VIII of only 50 years.

Smith and Berryman's (1986) paper revised the earlier work by incorporating not only seismological data of known large earthquakes and the recent instrumental record (up to 1982) but also geological studies on recent faults. The revision led to defining 15 characteristic regions with specific seismicity parameters and resulted in maps of revised return pe-
Table I. Return periods (years) of Modified Mercalli intensities for major cities in New Zealand from Smith (1976) and Smith and Berryman (1986).

\begin{tabular}{lrrrr}
\hline \hline & \multicolumn{2}{c}{ MMVII } & \multicolumn{2}{c}{ MMVIII } \\
\hline Auckland & 300 & 260 & 900 & 1400 \\
Hamilton & 150 & 9 & 500 & 420 \\
Rotorua & 80 & 45 & 250 & 190 \\
Napier & 30 & 42 & 80 & 140 \\
Wellington & 20 & 21 & 50 & 67 \\
Christchurch & 50 & 48 & 200 & 160 \\
Dunedin & 800 & 130 & $\sim 1500$ & 500 \\
\hline
\end{tabular}

riods. Figures 9a) and b) illustrate two of the maps. These results show only minor changes to the earlier estimates and table I shows the changes to the risks in some of the major cities.

The left hand column for each MM intensity is from the 1976 paper and the right hand column is from the 1986 paper. A study by Matuschka et al. (1985), drew on Smith and Berryman's work prior to its publication and presented contours of response spectral accelerations (with 5\% damping) for return periods of 50,150, 450 and 1000 years. These results are currently being incorporated into the New Zealand Building Code (Hutchison et al., 1986).

\subsection{Australia}

Compared with countries situated in tectonically active regions like Indonesia and Papua New Guinea, Australia is relatively aseismic. However, in the last 50 years seven earthquakes have taken place which have caused the equivalent of more than $\$ 1$ million damage and five earthquakes have been associated with surface faulting (BMR, 1992). The seismicity in the Australian continent is typical of that experienced in intra-plate environments (Denham, 1988). All the earthquakes occur within the crust $(<40 \mathrm{~km})$ and all the focal mechanisms are consistent with a compressed 


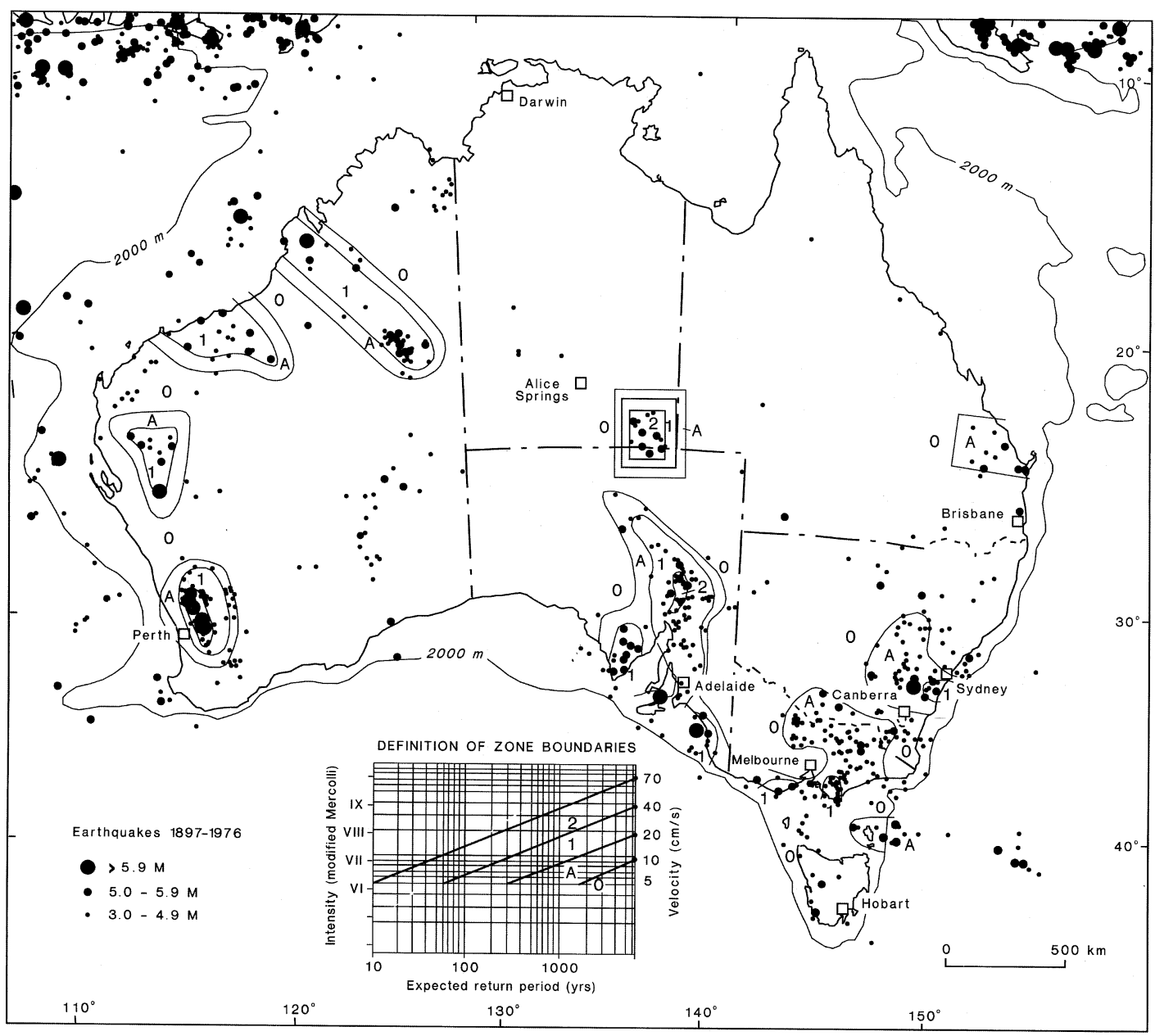

Fig. 10. 1979 earthquake risk map of Australia, showing zones for building code.

crust. In situ stress measurements, quarry floor pop-ups and borehole deformation observations confirm this compressive environment.

The first published earthquake risk study was by McEwin et al. (1976). The earthquake risk maps from this work were prepared from a very short data set (1960-1972) and extreme value methods were applied to obtain 50-year return periods for acceleration, velocity and intensity. The standard Kanai scaling rule was used with the Esteva and Rosenblueth (1964) coefficients.

The results from this work were used to derive the earthquake zoning map of Australia, which was incorporated with the Australian Building Code (AS 2121-1979). Figure 10 shows the four zones and the zoning map.

Gaull et al. (1990) published a revised set of maps using the standard Cornell-McGuire methodology. This technique starts by defining source zones, then adopting seismicity parameters and attenuation relations for each zone, to prepare the earthquake risk maps. Figure 11 shows the results for peak ground velocity for a 500 year return period. The expanded data base (1873-1988) enabled risk es- 


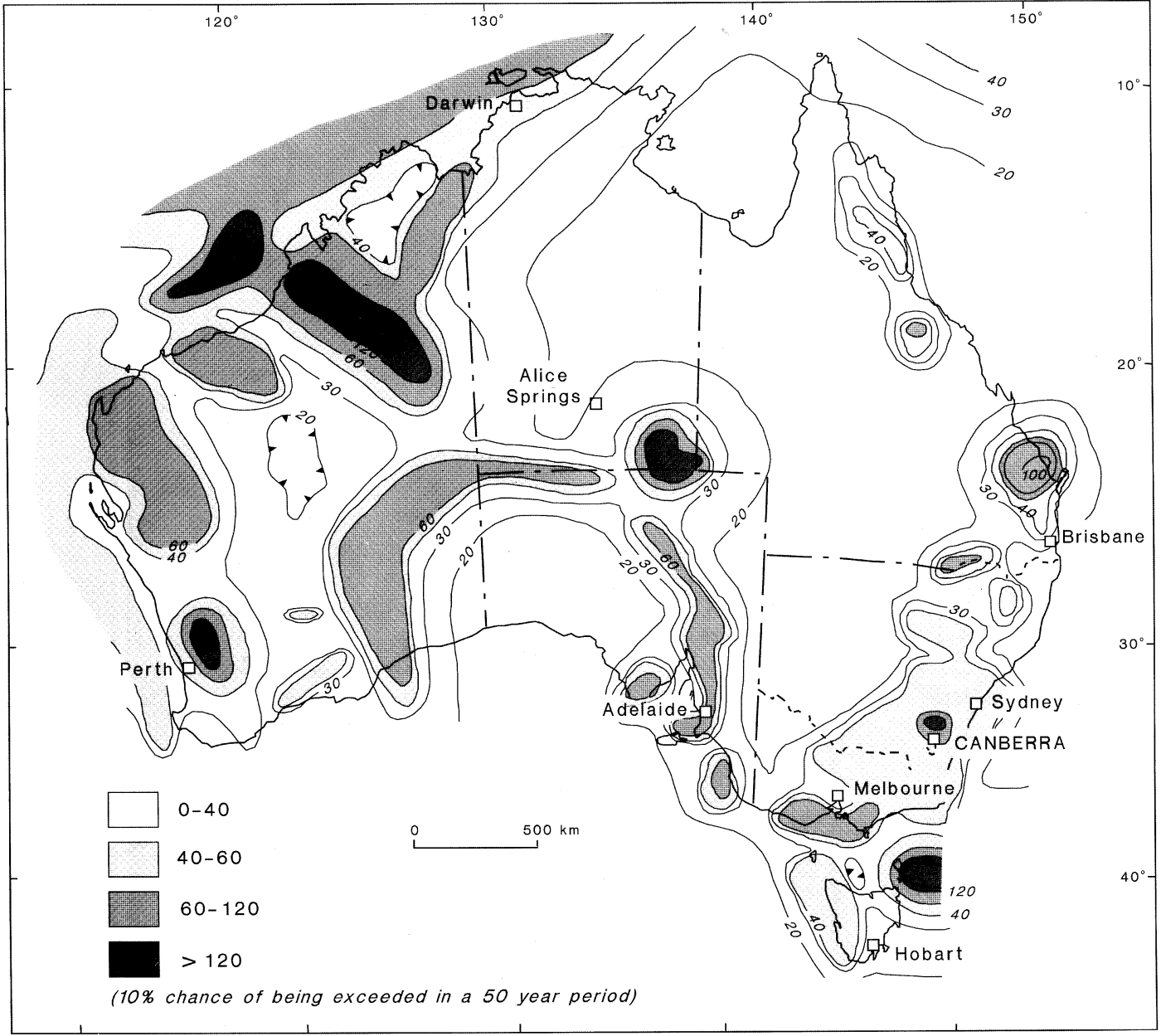

Fig. 11. Peak ground velocity $(\mathrm{mm} / \mathrm{s})$ with a $10 \%$ change of being exceeded in a 50 year period (from Gaull et al., 1990).

timates to be obtained for a larger area of the continent and this is shown in fig. 11.

The risk estimates for the capital cities were also modified as a result of this analysis. Table II compares the Gaull et al. (1990) estimates with those of the earlier McEwin et al.
(1976) results. The largest change is for Melbourne where the 500 year peak acceleration increases from less than $0.3 \mathrm{~m} / \mathrm{s}^{2}$ to 0.4 . Adelaide is still the capital with the highest risk.

After the Gaull et al. (1990) work was completed major earthquakes took place near 


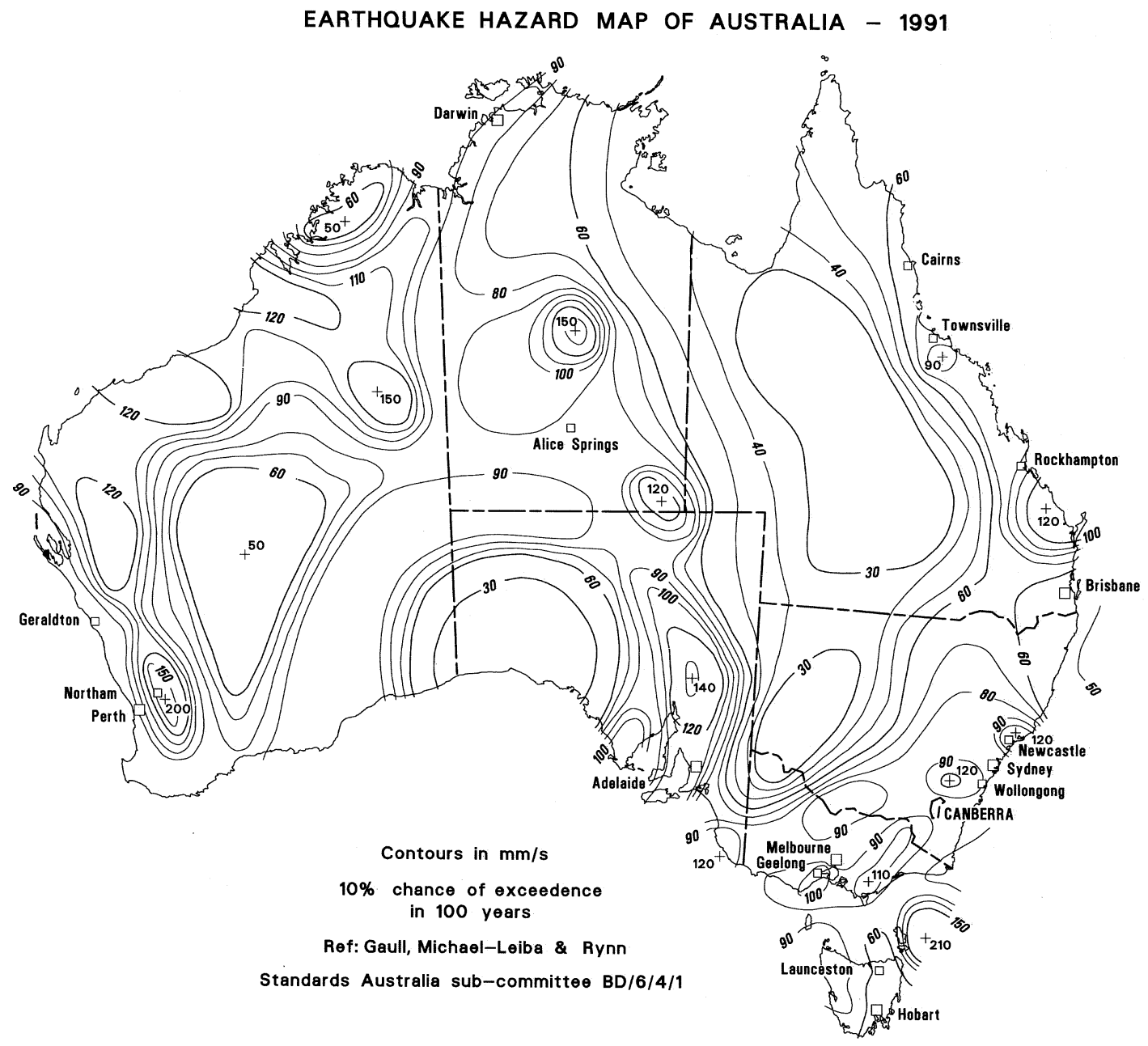

Fig. 12. Peak ground velocity $(\mathrm{cm} / \mathrm{s})$ with a $10 \%$ change of being exceeded in 100 year period (from draft Australian Building Code 1992).

Tennant Creek (1988) and Newcastle (1989). These events forced further amendments to the risk maps and fig. 12 shows the latest version for velocity as prepared by the Standards Australia Loading Commitee. The data set is from 1856-1990 and the map recognises that no part of the Australian continent is free from the possible occurrence of earthquakes. The map indicates that the risk has been «smeared» over the whole continent and the amplitudes of «bulls eyes» around areas of high seismicity in the recent past are reduced. 
Table II. Estimated peak acceleration for 500 year return period in $\mathrm{m} / \mathrm{s}^{2}$.

\begin{tabular}{lrr}
\hline \hline City & 1990 & 1976 \\
\hline Adelaide & 0.60 & 0.9 \\
Brisbane & 0.25 & $<0.3$ \\
Canberra & 0.55 & 0.3 \\
Darwin & 0.53 & $<0.3$ \\
Hobart & 0.25 & $<0.3$ \\
Melbourne & 0.40 & $<0.3$ \\
Perth & 0.44 & 0.4 \\
Sydney & 0.50 & 0.3 \\
\hline
\end{tabular}

This map is currently under review before being incorporated into the Australian Building Codes.

\section{Discussion and conclusions}

This review has revealed that for each country, where earthquake risk assessments have been made, the methods used are different. Furthermore, the parameters plotted on the risk maps are invariably different. These differences include the return periods selected and the parameters plotted (intensity, acceleration or velocity).

One of the problems in carrying out the studies outlined above is that, for the most part, local strong ground motion recordings were not included in the analyses. This was probably due to their unavailability.

In the last few years this situation has changed and in Papua New Guinea, New Zealand and Australia there is now a good data set of these recordings.

It would therefore seem appropriate for the risk assessments to be re-evaluated using these recordings and also consistent sets of attenuation relations. This does not mean that these must be the same in each region, rather that is possible to compare easily risk levels from country to country. At present this is very difficult and causes major problems in standardizing and comparing building codes. We also found that many of the countries in the South West Pacific, while having a high earthquake risk, have no quantitative risk assessments.

It is important that these assessments be carried out for the whole of the Australian/ Pacific plate margin from Papua New Guinea through to Macquarie Island.

\section{Acknowledgements}

We would like to thank Trevor Jones, Kevin McCue and Ian Ripper for helpful discussions in the preparation of this review and Gail Hill for preparing the diagrams.

\section{REFERENCES}

Beca, Carter, Hollings and Ferner Ltd. (1978): Indonesian earthquake study (6 volumes), Wellington, New Zealand (unpublished).

BMR (1992): Earthquake Monitoring in Australia: a plan for the future, report of technical committee instigated by Australian Government (unpublished).

Brooks, J.A. (1965): Earthquake activity and seismic risk in Papua and New Guinea, Aust. Bur. Miner. Resour., Geol. and Geophys. Rep., 74.

Denham, D. (1988): Australian Seismicity - the puzzle of the not so stable continent, Seismol. Res. Lett., 59, 235-240.

Esteva, R.L. and E. Rosenblueth (1964): Expectios de temblores distancias moderadas y grandes, Soc. Mex. Ing. Seis., 2, 1-18.

Everingham, I.B. 1986): A note on earthquake risk zoning in Fiji, Fiji, Miner. Resour. Dep. Note BP 33/14 (unpublished).

Gaull, B.A., M.O. Michael-Leiba and J.M.W. RynN (1990): Probabilistic earthquake risk maps of Australia, Aust. J. Earth Sci., 37, 169-187.

HATTORI, S. (1979): Seismic risk maps in the world (maximum acceleration and maximum particle velocity II) Balkan, Middle East, Southeast Asia, Central America, South America and others, Bull. Int. Inst. Seismol. Earthq. Eng., 17, 33-96.

Hutchison, D.L., A.L. Andrews, G.W. Butcher and D. Kolston (1986): Draft replacement of NZS 4203: 1984: Seismic provisions, Bull. N.Z. Nat. Soc. Earthq. Eng., 19, 158-166.

Jury, R.D., J.P. Hollings and I.A.N. Fraser (1982): The development of seismic zones and the evaluation of lateral loadings for earthquake resistant design of 
buildings in Papua New Guinea, Bull. N.Z. Soc. Earthq. Eng., 15, 3, 123-139.

KANAI, K. and I. SuzuKI (1968): Expectancy of the maximum velocity amplitude of earthquake motions at bed rock, Bull. Earthq. Res. Inst., 46, 663-666.

Matuschka, T, K.R. Berryman, A.J. O'Leary, G.H. McVerry, W.M. Mullholland and R.I. Skinner (1985): New Zealand seismic hazard analysis, Bull. N.Z. Nat. Soc. Earthq. Eng., 18, 313-322.

McCue, K.F. (1984): Discussion paper «The development of seismic zones and the evaluation of lateral loadings for earthquake resistant design of buildings in Papua New Guinea, edited by R.D. Jury, J.P. Hollings and Ian Fraser», Bull. N.Z. Soc. Earthq. Eng., 17, 4, 292296.
McEwin, A., R. Underwood and D. Denham (1976): Earthquake risk in Australia, BMR J. Aust. Geol. Geophys., 1, 15-21.

SMITH, W.D. (1976): Statistical estimates of the likelihood of earthquake shaking throughout New Zealand, Bull. N.Z. Soc. Earthq. Eng., 9, 4, 213-221.

SMITH, W.D. (1978a): Spatial distributions of felt intensities for New Zealand earthquakes, N.Z.J. Geol. Geophys., 21, 3, 293-311.

Smith, W.D. (1978b): Earthquake risk in New Zealand: statistical estimates, N.Z.J. Geol. Geophys., 21, 3, 313327.

SMITH, W.D. and K.R. BERRYMAN (1986): Earthquake hazard in New Zealand: inferences from seismology and geology, R.Soc. N.Z. Bull., 24, 223-243. 